\title{
Diabetes is associated with impairment of uterine contractility and high Caesarean section rate
}

\author{
S. Al-Qahtani • A. Heath • S. Quenby • F. Dawood • \\ R. Floyd $\cdot$ T. Burdyga $\cdot$ S. Wray
}

Received: 23 June 2011 / Accepted: 13 October 2011 /Published online: 19 November 2011

(C) The Author(s) 2011. This article is published with open access at Springerlink.com

\begin{abstract}
Aims/hypothesis The prevalence of births worldwide complicated by diabetes mellitus is increasing. In the $\mathrm{UK}$, for example, $<25 \%$ of diabetic women have a noninstrumental vaginal delivery. Strikingly, more than half the Caesarean sections (CS) in these patients are nonelective, but the reasons for this are not understood. We have tested the hypothesis that poor myometrial contractility as a consequence of the disease contributes to this high CS rate.

Methods We compared spontaneous, high K depolarisation and oxytocin-induced contractions from diabetic and matched control patients having an elective CS. To investigate the mechanism of any differences we measured
\end{abstract}

S. Al-Qahtani and A. Heath contributed equally to this study.

Electronic supplementary material The online version of this article (doi:10.1007/s00125-011-2371-6) contains peer-reviewed but unedited supplementary material, which is available to authorised users.

S. Al-Qahtani · A. Heath · R. Floyd · T. Burdyga $\cdot$ S. Wray $(\square)$

Department of Molecular and Cellular Physiology,

Institute of Translational Medicine, University of Liverpool,

Crown Street,

Liverpool L69 3BX, UK

e-mail: s.wray@liv.ac.uk

S. Quenby · F. Dawood

Liverpool Women's Hospital, University of Liverpool,

Liverpool, UK

S. Al-Qahtani

Department of Physiology, Medical College, Jazan University,

Jazan, Kingdom of Saudi Arabia

Present Address:

S. Quenby

Clinical Sciences Research Institute, University of Warwick,

Coventry, UK intracellular $\mathrm{Ca}$, and performed western blotting and compared the tissues histologically.

Results There was significantly decreased contraction amplitude and duration in uteri from diabetic compared with control patients, even when possible confounders such as BMI were analysed. Reduced intracellular calcium signals and expression of calcium entry channels were found in uteruses from diabetic patients, which, along with a reduction in muscle content found on histological examination, could explain the reduced force. Myometrium from diabetic patients was responsive to oxytocin, but still did not reach the levels found in non-diabetic patients.

Conclusions/interpretations These are the first data investigating myometrium in diabetic patients and they support the hypothesis that there is poorer contractility even in the presence of oxytocin. The underlying mechanism is related to reduced $\mathrm{Ca}$ channel expression and intracellular calcium signals and a decrease in muscle mass. We conclude that these factors significantly contribute to the increased emergency CS rate in diabetic patients.

Keywords Calcium · Diabetes · Force · Muscle histology · Myometrium · Oxytocin · Smooth muscle $\cdot$ Translational medicine

\begin{tabular}{|c|c|}
\hline \multicolumn{2}{|c|}{ Abbreviations } \\
\hline ANCOVA & Analysis of co-variance \\
\hline $\mathrm{au}$ & Arbitrary units \\
\hline CEMACH & $\begin{array}{l}\text { Confidential Enquiry into Maternal and Child } \\
\text { Health }\end{array}$ \\
\hline $\mathrm{CS}$ & Caesarean section \\
\hline GAPDH & Glyceraldehyde-3-phosphate dehydrogenase \\
\hline GTT & Glucose tolerance test \\
\hline $\mathrm{H} \& \mathrm{E}$ & Haematoxylin and eosin \\
\hline
\end{tabular}




\section{Introduction}

Worldwide, diabetes in pregnancy is associated with significant fetal and maternal morbidity and mortality. The prevalence of births complicated by pre-existing diabetes has increased by $50 \%$ in under a decade [1]. There is a consensus among researchers that the Caesarean section (CS) rate is higher in women with diabetes [2-4], with the Confidential Enquiry into Maternal and Child Health (CEMACH) reporting a rate of $67.4 \%$ [5]. The OR for risk of emergency $\mathrm{CS}$ in pregnancy complicated by a diabetic pregnancy is 3-4 $[2,6]$. CEMACH reported that $56 \%$ of CS were emergency operations not elective ones. CS in women with diabetes in pregnancy is associated with a 2.5 -fold increased risk of wound infection [7], and an increased risk of thrombosis and post-partum haemorrhage [4]. Despite the significant attendant morbidity associated with CS in diabetic pregnancies, the high CS rate in diabetic pregnancies is not understood.

Some authors suggest that the increased CS rate is due to the confounding factor of obesity [8]; however, other analyses have found diabetes mellitus to be an independent risk for CS $[2,9,10]$. Other putative factors are macrosomia, increased fetal distress and poor myometrial activity. Although macrosomia has been reported as a risk factor for CS in women with diabetes $[2,10]$, recent work has found that a reduction in macrosomia does not result in a concomitant reduction in CS rate [11-13]. Fetal distress is cited as a reason for emergency $\mathrm{CS}$ in diabetes [6], and fetuses of diabetic mothers are more vulnerable at term, with increased stillbirth rate $[3,4,6,14]$.

However, although fetal distress, macrosomia and obesity contribute to the increased emergency CS rate in diabetic pregnancies, prolonged labour and failed induction of labour accounted for $51 \%$ of emergency CS [6]. Therefore, poor myometrial contractility may be important. Further evidence to implicate poor myometrial contractility is that post-partum haemorrhage is six times more common in diabetic women [4]. Post-partum haemorrhage may be attributed to altered oxytocin responsiveness; however, clinical conditions linked to altered smooth muscle function with diabetes in other tissues include hypertension, gastric paresis, constipation, urine retention and vas deferens dysfunction. In vitro studies have found tissue-specific alterations in contractility [15-20], thus it is difficult to predict what the effects of diabetes mellitus may be on uterine contractions. There are few data concerning the effect of diabetes in the myometrium of any species and none on Ca signalling [21-24]. In the only study on human myometrium, which involved seven women who developed gestational diabetes, an increased response to endothelin-1 was reported [25], but no clinical information was presented.

Thus, the purpose of our study was to elucidate whether the contractility of human myometrium is impaired in women with pregnancies complicated by diabetes and to explore the underlying mechanisms. These data in turn will shed light on the question of whether their high CS rate may be partly explained by poor contractility.

\section{Methods}

Patient details Following ethics approval and informed consent, lower segment biopsies were taken at the time of elective CS from 40 patients with diabetes and 68 without. Hospital protocol is to perform elective CS at 39 weeks gestation for non-diabetic patients and 38 weeks for diabetic patients. Clinical and demographic data are presented in Tables 1, 2, 3. None of the patients in this study were in labour or had a multiple pregnancy.

All non-diabetic patients were screened initially with a detailed medical and obstetric history. If there is any factor in the history, for example previous big babies $>4.5 \mathrm{~kg}$, family history of diabetes, ethnicity (Asian), then patients automatically undergo a glucose tolerance test (GTT) between 24 and 28 weeks. Furthermore, if glycosuria is $>2+$ glucose detected in urine dipstix checked every 2 weeks, then this also prompts testing for GTT. Age $>35$ years without any risk factors does not lead to automatic GTT screening. In our unit we employ the WHO $75 \mathrm{~g}$ glucose load administered to fasting patients and then check glucose readings at 1 and $2 \mathrm{~h}$. By these criteria none of the patients in our control group had detectable gestational diabetes mellitus. This was a specific exclusion criterion. Other exclusion criteria were pre-eclampsia and medication likely to affect contractility.

Force and calcium measurements Tissue preparation and measurement of calcium were as described elsewhere [26, 27]. In brief, dissected muscle strips $(1 \times 3 \mathrm{~mm})$ were incubated in the $\mathrm{Ca}^{2+}$-sensitive indicator Indo-1 $(12.5 \mu \mathrm{mol} / \mathrm{l})$, for $2-3 \mathrm{~h}$ at room temperature. The strips were rinsed in physiological saline (see below) and then, with one end attached to a force transducer, mounted horizontally in a small $(500 \mu \mathrm{l})$ bath for simultaneous measurement of force and $\mathrm{Ca}$ signalling. Tissues were superfused $(3 \mathrm{ml} / \mathrm{min})$ with physiological saline at $35^{\circ} \mathrm{C}$. For $\mathrm{Ca}^{2+}$ measurement the tissues were excited at $340 \mathrm{~nm}$ and the Indo-1 fluorescence emitted at 400 and $500 \mathrm{~nm}$ was recorded. The ratio of these signals (F400/500) provides a measure of [Ca] [28]. Previous studies have shown that lower segment biopsies are a good model for studying human myometrial contractility [29].

Solutions Physiological saline with composition (mmol/l) $154 \mathrm{NaCl}, 5.4 \mathrm{KCl}, 1.2 \mathrm{MgSO}_{4}, 8$ glucose, $2 \mathrm{CaCl}_{2}, 11$ Hepes; $\mathrm{pH}$ 7.4. In some experiments oxytocin $(10 \mathrm{nmol} / \mathrm{l})$ or the $\mathrm{Ca}^{2+}$ channel agonist BAY K-8644 $(1 \mu \mathrm{mol} / \mathrm{l})$ were added to the perfusate. 
Table 1 Patient details: type 1 diabetes mellitus $(n=18)$

\begin{tabular}{|c|c|c|c|c|c|c|c|c|c|}
\hline \multirow{2}{*}{$\begin{array}{l}\text { Age } \\
\text { (years) }\end{array}$} & \multirow{2}{*}{$\begin{array}{l}\mathrm{BMI} \\
\left(\mathrm{kg} / \mathrm{m}^{2}\right)\end{array}$} & \multirow[t]{2}{*}{ Diabetic complications } & \multicolumn{2}{|c|}{$\mathrm{HbA}_{1 \mathrm{c}}$ (range) } & \multirow[t]{2}{*}{ Type of insulin } & \multirow[t]{2}{*}{ Parity } & \multirow{2}{*}{$\begin{array}{l}\text { Gestational } \\
\text { age (weeks) }\end{array}$} & \multirow{2}{*}{$\begin{array}{l}\text { Birthweight } \\
(\mathrm{kg})\end{array}$} & \multirow[t]{2}{*}{ Caesarean indication } \\
\hline & & & $\%$ & $\mathrm{mmol} / \mathrm{mol}$ & & & & & \\
\hline 40 & 31.6 & None & $6.1-6.2$ & $43-44$ & Humulin; humalog & 1 & 38 & 3.69 & Previous CS \\
\hline 40 & 22.3 & None & $5.9-6.4$ & $41-46$ & Humalog; lantus & 1 & 38 & 3.49 & Maternal request \\
\hline 26 & 28.9 & Retinopathy & $6.4-6.6$ & $46-49$ & CSII & 0 & $35+2$ & 2.18 & Maternal request \\
\hline 24 & 30.1 & Microalbuminuria & $7.9-8.1$ & $63-65$ & Novorapid, glargine ${ }^{\mathrm{a}}$ & 0 & 38 & 3.34 & Previous CS \\
\hline 36 & 24.6 & None & $6.0-7.0$ & $42-53$ & $\begin{array}{l}\text { Novorapid, lantus } \\
\text { CSII }\end{array}$ & 1 & $37+4$ & 4.5 & Diabetes \\
\hline 36 & 22.4 & Previous nephropathy & $6.5-6.8$ & $48-51$ & CSII & 1 & $36+4$ & 4.42 & Maternal reason \\
\hline 27 & 41.9 & None & 7.9-9.7 & $63-83$ & Humalog; lantus & 2 & $35+3$ & 4.48 & Diabetes \\
\hline 39 & 30 & Retinopathy & $6.4-8.2$ & $46-66$ & Humalog; humulin & 0 & $34+0$ & 2.58 & $\begin{array}{l}\text { Previous CS/ } \\
\text { maternal request }\end{array}$ \\
\hline 44 & 31.2 & Vascular & 6.3 & 45 & Insulin & 3 & $36+4$ & 2.72 & Maternal reason \\
\hline 29 & 22.3 & None & $5.7-6.3$ & $39-45$ & Insulin & 1 & 38 & 3.26 & Diabetes \\
\hline 28 & 43 & Nephropathy & $7.1-7.5$ & $54-59$ & Novorapid, lantus & 3 & $35+2$ & 4.37 & Diabetes \\
\hline 34 & 43.8 & None & 6.7 & 50 & Insulin & 1 & $37+1$ & 4.31 & Previous CS \\
\hline 37 & 22.6 & Retinopathy & 6 & 42 & Novorapid, lantus & 3 & $32+6$ & 2.48 & Maternal reason \\
\hline 38 & 25.2 & Hypertension & 6.5 & 48 & Novorapid, lantus & 3 & $36+3$ & 4.115 & Previous CS \\
\hline 27 & 24.2 & None & 5.9 & 41 & CSII & 3 & $33+5$ & 2.46 & Breech \\
\hline 41 & 46.2 & Hypertension & 6.1 & 43 & Novorapid, lantus & 1 & 37.5 & 3.29 & Previous CS \\
\hline 36 & 24.8 & $\begin{array}{l}\text { Retinopathy and } \\
\text { nephropathy }\end{array}$ & 5 & 31 & Novorapid, lantus & 0 & 37 & 3.27 & Diabetes \\
\hline 40 & 36.5 & None & $5.5-6.0$ & $37-42$ & Novorapid & 2 & 38 & 3.75 & Previous CS \\
\hline
\end{tabular}

${ }^{\mathrm{a}}$ Insulin glargine (A21Gly,B31Arg,B32Arg human insulin)

Protocol and analysis Muscle strips generating stable spontaneous contractions were exposed to $40 \mathrm{mmol} / \mathrm{l} \mathrm{KCl}$ solution $\left(\mathrm{K}^{+}\right.$substituted for $\mathrm{Na}$ in the physiological saline) for $2 \mathrm{~min}$ to obtain a measure of maximal activity, which could also be used to standardise between preparations. After stable contractions were established, a control period of $60 \mathrm{~min}$ was obtained before the physiological solution was altered. The frequency of contractions was obtained over this control period. The last three contractions of this control period were used to determine average peak amplitude and duration at half-height. The integral of force (area under the curve, in arbitrary units [au]) was obtained over the last $20 \mathrm{~min}$ of the control period. Only one result was obtained from each patient, thus $\mathrm{n}$ is the number of patients. Data were obtained and analysed in a blinded fashion.

Histology Paraffin-embedded $5 \mu \mathrm{m}$ sections were made from ten control and diabetic myometria, and stained with both haematoxylin and eosin (H\&E) to allow measurement of muscle bundles and uterine histology. Sections were also stained with Masson's Trichrome to allow measurement of collagen deposition compared with muscle. Samples were viewed at $\times 40$ magnification by two independent observers blinded to the origin of the samples. Muscle bundles were assessed in semi-quantitative fashion in terms of muscle bundle size, organisation and separation. To determine muscle percentage and collagen deposition, images were captured using Eclipsenet software (Nikon, Nikon UK, Kingston upon Thames, UK) from ten randomly selected regions per sample, imported into ImageJ freeware (NIH, Bethsheda, MD, USA) and analysed using colour-based thresholding [30].

Western blotting and immunohistochemistry Proteins were extracted, quantified and separated by SDS-PAGE and transferred to polyvinylidene difluoride (PVDF) membranes using previously described methods [31]. Membranes were probed overnight with agitation at $4^{\circ} \mathrm{C}$ with primary antibodies as follows: rabbit polyclonal L-type calcium channel $\alpha 1 \mathrm{C}$ 1:200 (Alomone) or mouse monoclonal glyceraldehyde-3-phosphate dehydrogenase (GAPDH) 1:400 (AbCam) diluted in 5\% non-fat dried milk in TBS/0.1\% (vol./vol.) Tween 20 (TBST) or 5\% protease-free bovine serum albumin in TBST respectively. Immunoreactive sites were revealed using goat anti-rabbit or goat anti-mouse IgG conjugated to horseradish peroxidase and SuperSignal West Pico substrate (Pierce-Perbio Science, Cramlington, UK).

Tissue microarrays containing formalin-fixed paraffinembedded samples of ten diabetic and ten non-diabetic myometrial tissues were processed as described in detail elsewhere [32]. Microarrays also contained rat heart and 
Table 2 Gestational diabetes mellitus $(n=22)$

\begin{tabular}{|c|c|c|c|c|c|c|c|c|}
\hline \multirow{2}{*}{$\begin{array}{l}\text { Age } \\
\text { (years) }\end{array}$} & \multirow{2}{*}{$\begin{array}{l}\text { BMI } \\
\left(\mathrm{kg} / \mathrm{m}^{2}\right)\end{array}$} & \multicolumn{2}{|c|}{$\mathrm{HbA}_{1 \mathrm{c}}$ (range) } & \multirow[t]{2}{*}{ Type of insulin } & \multirow[t]{2}{*}{ Parity } & \multirow{2}{*}{$\begin{array}{l}\text { Gestational } \\
\text { age (weeks) }\end{array}$} & \multirow{2}{*}{$\begin{array}{l}\text { Birthweight } \\
(\mathrm{kg})\end{array}$} & \multirow{2}{*}{$\begin{array}{l}\text { Caesarean } \\
\text { indication }\end{array}$} \\
\hline & & $\%$ & $\mathrm{mmol} / \mathrm{mol}$ & & & & & \\
\hline 26 & 35.4 & $5.4-7.0$ & $36-53$ & Insulin: novomix & 1 & 38 & 3.71 & Previous CS \\
\hline 29 & 42.5 & $6.9-7.2$ & $52-55$ & Metformin and insulin:novomix & 1 & $38+1$ & 4.16 & Previous CS \\
\hline 30 & 40.7 & $5.1-5.6$ & $32-38$ & Metformin and insulin:lantus & 1 & 38 & 3.2 & Previous CS \\
\hline 33 & 26.5 & $5.3-5.6$ & $34-38$ & Diet only & 1 & 38 & 3.57 & Previous CS \\
\hline 38 & 28.9 & $5.1-5.3$ & $32-34$ & Diet only & 1 & 39 & 3.57 & Previous CS \\
\hline 37 & 35.6 & $5.6-5.7$ & $38-39$ & Diet only & 1 & 38 & 3.74 & Previous CS \\
\hline 33 & 29.8 & $4.4-5.8$ & $25-40$ & Diet only & 2 & $37+6$ & 4.83 & \\
\hline 38 & 27.8 & $5.4-7.0$ & $36-53$ & Diet only & 2 & $36+5$ & 2.78 & Previous CS \\
\hline 31 & 24 & 5.1 & 32 & Insulin: lantus & 1 & $38+6$ & 3.03 & Previous CS \\
\hline 38 & 38 & $7.0-9.3$ & $53-78$ & Insulins: novorapid and lantus & 1 & $38+1$ & 4.76 & Previous CS \\
\hline 36 & 31.5 & 7.4 & 57 & Metformin & 1 & $38+3$ & 3.9 & Previous CS \\
\hline 35 & 33.7 & $4.1-6.2$ & $21-44$ & Insulins: novorapid and lantus & 2 & $38+1$ & 3.3 & Diabetes \\
\hline 35 & 19.4 & $4.2-6.5$ & $22-48$ & Diet only & 3 & $38+2$ & 3.25 & Diabetes \\
\hline 29 & 24.8 & $5.8-6.0$ & $43-42$ & Insulins: novarapid and lantus & 0 & 38 & 3.98 & Previous CS \\
\hline 30 & 21.5 & $4.5-6.8$ & $26-51$ & Insulin: novorapid & 1 & $37+5$ & 4.15 & Breech \\
\hline 32 & 28.1 & 6.4 & 46 & Diet only & 1 & $37+1$ & 4.31 & Previous CS \\
\hline 27 & 50.1 & 4.7 & 28 & Diet only & 1 & $37+5$ & 4.11 & Previous CS \\
\hline 36 & 23.8 & 6.3 & 45 & Diet only & 1 & $38+3$ & 2.68 & Breech \\
\hline 29 & 53.1 & 6.7 & 50 & Diet only & 1 & 36 & 3.23 & Hypertension \\
\hline 27 & 50.7 & 8.5 & 69 & Novorapid, lantus & 1 & $37+4$ & 3.23 & Previous CS \\
\hline 37 & 32.4 & $5.7-5.9$ & $39-41$ & Novorapid, lantus & 1 & $37+3$ & 5.05 & Previous CS \\
\hline 32 & 26.2 & 5.5 & 37 & Novorapid & 2 & 38 & 3.8 & Previous CS \\
\hline
\end{tabular}

skeletal muscle as positive control tissues. Immunohistochemistry was performed as described previously [31] and [33] using rabbit polyclonal L-type calcium channel $\alpha 1 \mathrm{C}$ (Alomone) antibody diluted 1:100 in TBST/1\% protease-free bovine serum albumin applied overnight at $4{ }^{\circ} \mathrm{C}$. Control experiments were performed by incubating slides with nonimmune rabbit serum or by omitting primary antibody, or by peptide competition of $1 \mu \mathrm{g}$ peptide per $1 \mu \mathrm{g}$ antibody. Image capture of immunostained sections was performed using an Olympus BX51 microscope with a PL-A662 firewire camera (PixeLINK, Ottawa, ON, Canada) using a $\times 20$ objective. Western blot signal quantification was carried out using ImageJ for Windows and the relative band intensities corresponding to L-type calcium channel expression are expressed as a percentage of the GAPDH internal control for each sample. Blots from three repeat experiments were scanned in 128 shades of grey and thresholding was used to segment blots into objects of interest.

Chemicals were from Sigma, Dorset, UK unless indicated otherwise.

Table 3 Demographics of diabetic and non-diabetic patient groups

\begin{tabular}{lcrr}
\hline Variable & Type 1 diabetes mellitus & Gestational diabetes mellitus & Non-diabetic controls \\
\hline Age (years) & $36(28-39)$ & $33(30-37)$ & $33(24-44)$ \\
BMI (kg/m $\left.{ }^{2}\right)$ & $29.5(24-32)$ & $29(26-35)$ & $27(19-45)$ \\
Gestational age (weeks) & $37(35-37)$ & $38(37-38)$ & $39(37-40)$ \\
Birthweight $(\mathrm{kg})$ & $3.42(2.72-4.30)$ & $3.73(3.20-4.20)$ & $3.48(2.69-4.48)$ \\
\hline
\end{tabular}

Data are median (interquartile range) from the patient groups

All data in all groups were from women having an elective Caesarean section, i.e. they were not in labour. Elective section before 37 weeks in non-diabetic patients was due to placenta praevia, and before 38 weeks was due to rhesus disease, maternal request, placenta praevia or unstable See ESM Table 1 for full control patient data 
Statistics The $\mathrm{n}$ numbers represent different patient biopsies and only one set of data was obtained from each biopsy. Experimental data were analysed using Mann-Whitney $U$, Wilcoxon, analysis of co-variance (ANCOVA) or Student's $t$ test with significance taken at $p<0.05$. Results are expressed as median (first and third quartile) or mean \pm SEM.

\section{Results}

Patients There were no significant differences in maternal age, BMI and birthweight between type 1 diabetic $(n=18)$, gestational diabetic $(n=22)$ and non-diabetic patients $(n=68$; Tables 1, 2, 3, and electronic supplementary material [ESM] Table 1). Type 1 diabetic patients were delivered typically at 38 weeks in order to avoid unheralded stillbirth, or earlier if there was fetal compromise or deterioration in maternal health. However, the mean gestational age of delivery for the type 1 diabetic patient remains comparable with both the gestational diabetic group and the control group, as shown.

Spontaneous contractility There were significant differences in the contractions between samples from diabetic and non-diabetic patients; the contractions were smaller and shorter-lasting in diabetic patients (Fig. 1c, Table 4). When normalised to high $\mathrm{K}$ contractions (100\%) these variables, were also significantly lower in the diabetic patients, $65 \%$ $(55,82 \%)$ compared with $80 \%(61,90 \%)$ in non-diabetic controls; see also Fig. 1c. The significant decreases in contractility resulted in the AUC also being significantly less in diabetic patients, $2.1(1.1,3.5)$ au, compared with non-diabetic controls, $8.7(4.0,14.5)$ au. ANCOVA was used to determine the effects of possible confounders: age, BMI, birthweight and gestational age. The decreased contractility in myometrium from diabetic patients remained significant $(p<0.05)$.

The effect of oxytocin Oxytocin was added to the perfusate after spontaneous contractions had been established. In non-diabetic patients $(n=7)$, it produced a marked increase in uterine contractility and underlying $\mathrm{Ca}^{2+}$ signals (Fig. 1b). Thus the amplitude and AUC of both contractions and $\mathrm{Ca}^{2+}$ showed significant increases; when compared with spontaneous contractions (100\%), the mean amplitude and contraction AUC were $184 \pm 15 \%$ and $337 \pm 46 \%$ au, respectively. In diabetic patients $(n=6)$, oxytocin also produced a significant increase in both, which were not significantly different from that found in control group, $219 \pm 26 \%$ and $332 \pm 83 \%$ respectively (Fig. 1d). However, in the diabetic samples contractility, even when stimulated with oxytocin, remained significantly reduced when compared with oxytocin stimulation in non-diabetic patients.
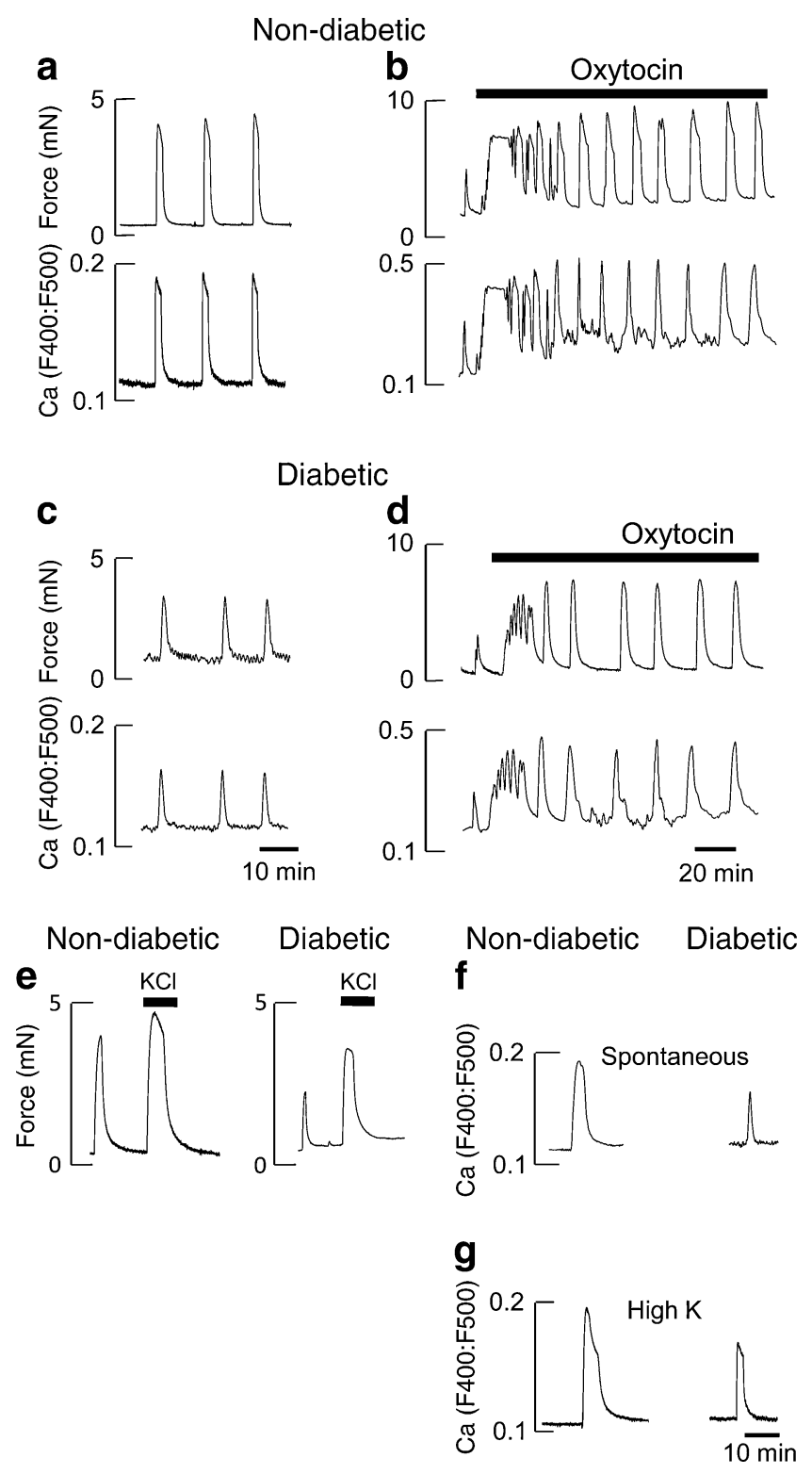

Fig. 1 Spontaneous, oxytocin and high K-induced activity. Spontaneous and oxytocin-induced activity. a and $\mathbf{c}$ Simultaneous measurements of force and $\mathrm{Ca}$ (Indo-1) in myometrium from non-diabetic (a) and diabetic patients (c) during spontaneous activity. Typical records from 40 diabetic and 68 non-diabetic patients. Effects of $10 \mathrm{nmol} / 1$ oxytocin (b and d), typical of at least five other records for both groups. e Comparison of the effects of $40 \mathrm{mmol} / \mathrm{l} \mathrm{K}$ stimulation after a spontaneous contraction in non-diabetic and diabetic myometrium, typical of 13 others. $\mathbf{f}$ and $\mathbf{g}$ Representative Indo-1 records showing the Ca signals in response to spontaneous (f) and high $\mathrm{K}$ stimulation (g) in samples from non-diabetic and diabetic patients. In this and subsequent samples all data were obtained on myometrium from elective CS biopsies at $35^{\circ} \mathrm{C}$ and superfused physiological solution containing $8 \mathrm{mmol} / \mathrm{l}$ glucose

High $\mathrm{K}$ solution As a significant decrease in $\mathrm{Ca}^{2+}$ transient amplitude and duration was found in uteruses from diabetic patients, we investigated if this was due to a lack of activation of the L-type $\mathrm{Ca}^{2+}$ channels by using high $\mathrm{K}^{+}$ depolarisation to open calcium channels. 
Table 4 Variables of contraction and $\mathrm{Ca}$ transients in diabetic and non-diabetic patients

\begin{tabular}{|c|c|c|c|c|c|c|}
\hline \multirow[t]{3}{*}{ Variable } & \multicolumn{4}{|c|}{ Spontaneous contractions } & \multicolumn{2}{|c|}{ High $\mathrm{K}$ contraction } \\
\hline & \multicolumn{2}{|l|}{ Contractions } & \multicolumn{2}{|l|}{ Ca signals } & \multirow[b]{2}{*}{$\begin{array}{l}\text { Non-diabetic } \\
(n=14)\end{array}$} & \multirow[b]{2}{*}{$\begin{array}{l}\text { Diabetic } \\
(n=14)\end{array}$} \\
\hline & $\begin{array}{l}\text { Non-diabetic } \\
(n=68)\end{array}$ & $\begin{array}{l}\text { Diabetic } \\
(n=40)\end{array}$ & $\begin{array}{l}\text { Non-diabetic } \\
(n=15)\end{array}$ & Diabetic $(n=9)$ & & \\
\hline Frequency (contraction/h) & $8(6,12)$ & $7(5,13)$ & - & - & - & - \\
\hline Amplitude $(\mathrm{mN})$ & $2.4(1.2,4.5)$ & $1.5(0.9,2.6)^{*}$ & $0.7(0.3,1.0)$ & $0.2(0.1,0.5)$ & $3(1.3,4.5)$ & $1.5(0.8,3.0)^{*}$ \\
\hline Duration (min) & $1.7(1.1,2.5)$ & $0.9(0.6,1.3)^{*}$ & $2.0(1.2,3.3)$ & $1.0(0.8,1.7)^{*}$ & $2.1(1.3,3.6)$ & $1.2(0.8,1.8)^{*}$ \\
\hline AUC (au) & $8.7(4.0,14.5)$ & $2.1(1.1,3.5)^{*}$ & $4.4(2.0,7.2)$ & $1.1(0.6,1.7)^{*}$ & $5.4(3.5,16.4)$ & $2.8(1.3,3.5)^{*}$ \\
\hline Relaxation rate (min) & N/A & N/A & $5.0(4.7,9.1)$ & $2.4(0.7,4.5)^{*}$ & N/A & N/A \\
\hline
\end{tabular}

Median data with first and third quartiles in parenthesis

AUC for spontaneous contractions obtained over the last $20 \mathrm{~min}$ of the control period, whereas for $\mathrm{KCl}$ it was obtained from one contraction developed in response to $2 \mathrm{~min}$ exposure to high $\mathrm{KCl}$

$* p<0.05$

N/A, not available

As can be seen (Fig. 1c, $n=14$ in each group), $40 \mathrm{mmol} / 1 \mathrm{~K}^{+}$produced a large increase in force, which plateaus and then declines. A similar response pattern occurred in both types of biopsy but the amplitude was significantly greater in non-diabetic $3.0 \mathrm{mN}(1.3,4.5)$ compared with diabetic samples $1.5(0.8,3.0)$. There were also significant differences in the duration and AUC (Table 4).

Ca channels Immunohistochemical studies revealed the $\alpha_{1 \mathrm{C}}$ subunit in myocyte membranes (Fig. 2a, non-diabetic myometrium $n=10$, diabetic myometrium, $n=10$ ). Figure 2a (bottom) shows controls and negative control with antibody-peptide adsorption. Relative abundance of L-type calcium channel immunoreactivity was reduced in diabetic samples compared with age-matched myometrial samples from non-diabetic patients. Western blotting revealed a $\sim 220 \mathrm{kDa}$ band, the predicted molecular weight of L-type calcium channels $(n=9$ non-diabetic and ten diabetic patients, Fig. 2b). Analysis of signal intensity revealed a small but significant decrease in L-type calcium channel expression in diabetic (63.64 $\pm 3.694 \%)$ compared with non-diabetic myometrium $(76.85 \pm 3.911 \%)$ when expressed as a percentage of GAPDH internal control expression.

As can be seen in Figs 1 and 2, the changes in contractility in both non-diabetic and diabetic myometrium, whether occurring spontaneously or in response to oxytocin or high $\mathrm{K}^{+}$solutions, were a reflection of the changes in intracellular $\left[\mathrm{Ca}^{2+}\right]$, as recorded by Indo-1 fluorescence. Table 2 gives the time to peak amplitude, duration at halfheight, relaxation time and AUC of the $\mathrm{Ca}^{2+}$ transients. All apart from time to peak were significantly reduced in the diabetic samples. To further investigate the mechanism underlying the transient fall in $\mathrm{Ca}^{2+}$ in diabetic samples, we used the agonist BAY K-8644, which increases the open probability of L-type $\mathrm{Ca}^{2+}$ channels. Figure $2 \mathrm{c}$ shows the effect of the L-type $\mathrm{Ca}^{2+}$ channel opener Bay K8644 $(1 \mu \mathrm{mol} / \mathrm{l})$. Application of BAY K-8644 produced a large stimulation of $\mathrm{Ca}^{2+}$ entry and augmentation of force in both diabetic $(n=5)$ and non-diabetic $(n=5)$ samples. Baseline $\mathrm{Ca}^{2+}$ and force were also elevated. As can be seen in Fig. 2c, however, diabetic samples showed significantly smaller increments in AUC for both force and $\mathrm{Ca}^{2+}$, compared with control values of $100 \%$ : in diabetic patients their increases were $194 \pm 36 \%$ and $124 \pm 20 \%$, respectively, whereas in non-diabetic patients these values were $353 \pm 48 \%$ and $224 \pm 36 \%$.

Histology Light microscopic examination of H\&E-stained myometrial sections from ten diabetic and ten non-diabetic patients were examined. There were no differences in myometrial appearance from diabetic samples; muscle bundle size, organisation and separation were all normal (Fig. 2d). The percentage muscle for each section was calculated and the overall average taken for both groups. There was a small but significant $(p<0.001)$ reduction in the muscle content of

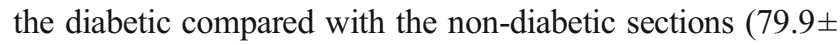
$1.1 \%$ vs $86.7 \pm 1.2 \%$ ) respectively. Masson's Trichrome stained sections were used to investigate if this difference in muscle content was due to alterations in collagen deposition. There was a small but significant $(p<0.02)$ reduction in the muscle content of the diabetic compared with the non-diabetic sections $(44.8 \pm 2.2 \%$ vs $54.1 \pm 1.3 \%)$ respectively (Fig. 2e). Analysis of the collagen deposition showed a non-significant change in the collagen deposition in the diabetic group $(22.1 \pm 1.9 \%$ vs $26.2 \pm 2.9 \%)$.

Effect of diet versus insulin diabetic control The majority of patients were using insulin to control their blood glucose 
Fig. 2 Uterine histology and $\mathrm{Ca}$ channels. a Tissue distribution of L-type calcium channels. Immunohistochemical localisation of L-type calcium channels in non-diabetic and diabetic myometrium with positive and negative controls underneath. Scale bar, $50 \mu \mathrm{m}$. b Quantification of L-type calcium channel expression. Densitometric western blot quantification of L-type calcium channels in non-diabetic and diabetic patients. c Effect of Bay K-8644 stimulation. Simultaneous measurements of force and $\mathrm{Ca}$ (Indo-1) in myometrium from non-diabetic and diabetic patients during spontaneous activity and with application of $1 \mu \mathrm{mol} / 1$ of the Ca channel agonist, Bay K-8644. d and e Myometrial histology. d H\&E. e Masson's Trichrome-stained uterine sections from nondiabetic and diabetic patients. Scale bar, $50 \mu \mathrm{m}$. Significant difference, ${ }^{*} p<0.05$

\section{a}
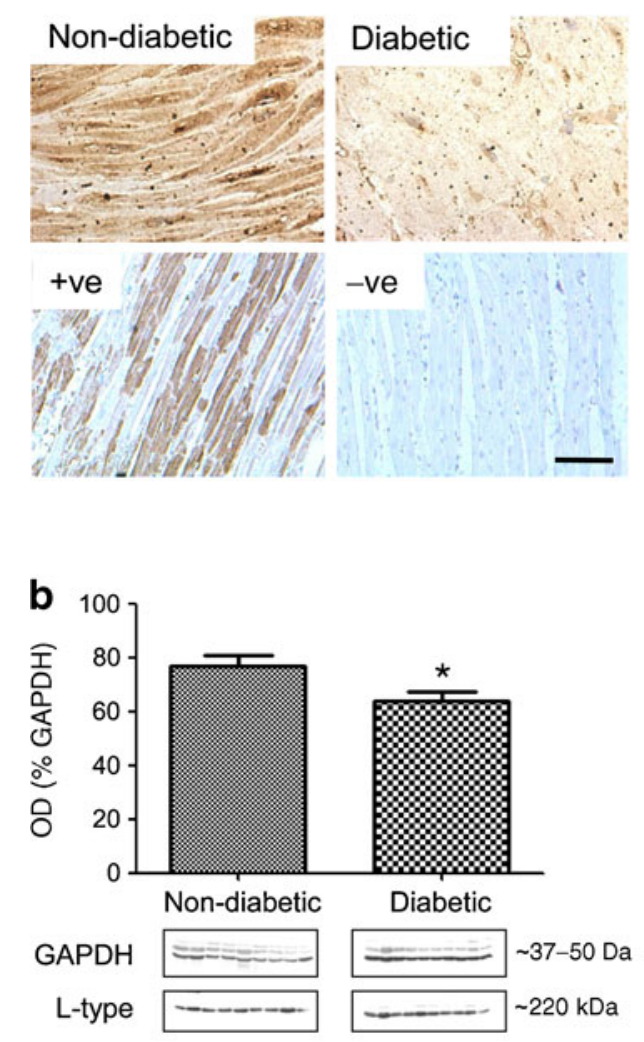

C

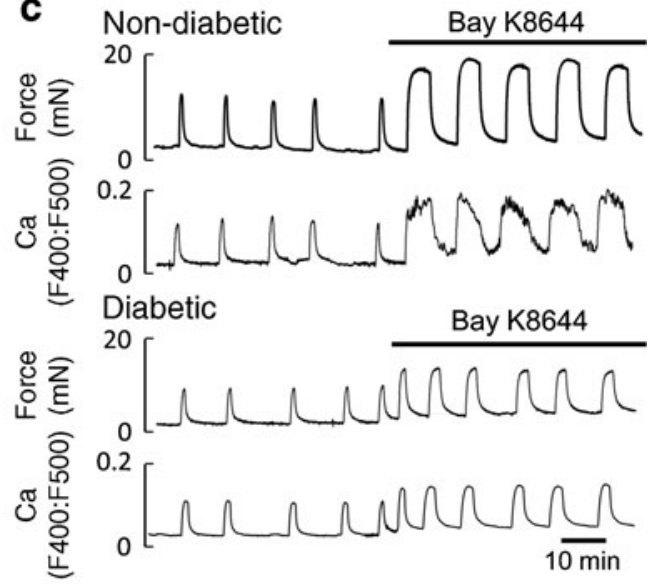

d

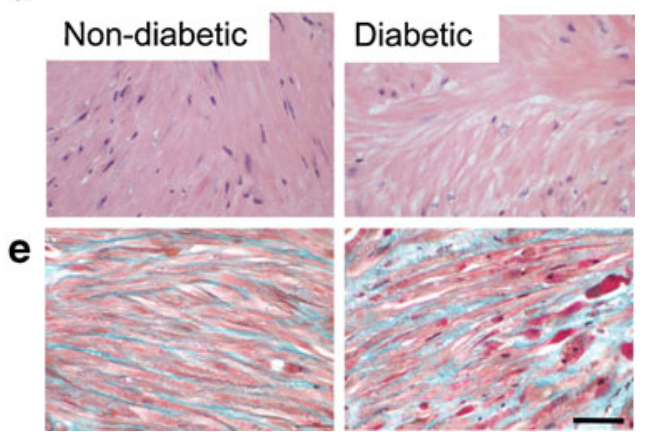

levels, but nine gestational diabetic patients used dietary control alone. We therefore analysed them separately and compared the data to those for patients taking insulin. There were no significant differences between groups (data not shown).

\section{Discussion}

By studying a large number of uterine biopsies from pregnant diabetic patients we have found that when compared with matched non-diabetic patients, contractility is significantly reduced. Analysis of the diabetic patients showed that these findings held even when insulin-treated were compared with diet-controlled gestational diabetic patients. Contractility was poorer in the diabetic samples whether arising spontaneously, with oxytocin or high $\mathrm{K}^{+}$; calcium channel expression and signalling were reduced and are likely to account for the reduction in contractility. The reductions in $\mathrm{Ca}$ signals are consistent with the reduced $\mathrm{Ca}^{2+}$ channel expression and function in myometria from diabetic patients. The small but significant decrease in myometrial mass will also contribute to the decreased contractility. Our data suggest that in labour, myometrial activity will be poorer in diabetic patients and will lead to an increase risk of CS even when controlling for other factors such as obesity and hypertension.
Effects on contractions There are few studies investigating myometrial contractility in diabetes with which to compare our data. Force in isolated uteruses from diabetic rats was decreased compared with control rats [22], consistent with our data on human myometrium. An earlier report on human myometrium from diabetic patients noted that the stability of contractions, as measured by their decrement within $1 \mathrm{~h}$, was reduced in diabetic patients, that is, force was reduced faster [25]. However, although we found the amplitude and duration of contractions to be reduced in diabetic patients, this activity was well maintained for several hours. Unfortunately, Kaya et al. [25] did not compare contraction amplitude or any other parameters of contraction. Thus, our study is the first to document the changes in contractility in human myometria from diabetic patients, and it reveals that the spontaneous contractions and their accompanying $\mathrm{Ca}$ transients were significantly lower in diabetic patients compared with non-diabetic patients. The amplitude and duration were significantly decreased, so much so that the AUC was only half that of the non-diabetic patients.

No previous work has investigated the effect of oxytocin on human diabetic myometrium. A previous study on myometria from diabetic rats reported that oxytocin stimulation was similar to that in control rats [22], whereas McMurtrie et al. [21] found maximal responses reduced. We found that oxytocin increased myometrial force and calcium transients in non-diabetic and diabetic patients 
about equally. Thus, it appears that the diabetic uterus can respond to oxytocin, making it unlikely that oxytocin receptors have been downregulated or that the signalling pathways elicited by it are impaired. In other smooth muscles mainly studied in diabetic animals, both increased and decreased agonist responses are reported (e.g. [34-36]) and no consistent mechanism has been identified.

Our data with high $\mathrm{K}^{+}$stimulation showed a significant decrease in amplitude of force and $\mathrm{Ca}$ rise in diabetic samples. There is no consistency in the reported effects of high $\mathrm{K}+$ on other smooth muscle preparations from diabetic tissues, with similar findings to ours reported by some [36$38]$, but no change or increase by others [20,39]. Our data are consistent with those of Wang et al. [40], who also found decreased L-type $\mathrm{Ca}^{2+}$ current density discussed below, but our data could also be due to decreased channel expression and altered channel kinetics.

Histology The differences in force output in the uterine biopsies from patients with diabetic pregnancy may be due to structural changes. No obvious differences in cellular abundance or orientation were seen at the light microscopic level, but there was a difference in the amount of muscle present. There have been no other histological studies of diabetic human myometrium and only one electron microscopic study performed in rats [21]. These authors saw no differences in nuclei or mitochondria between streptozotocintreated and control rats but noted, with no quantification or elaboration, that the number and cellular orientation of myofilaments in euglycaemic animals 'appeared different'.

Ca signalling Myometrial contractility is dependent on calcium influx via voltage-gated channels, and hence on membrane potential $[41,42]$. Changes in myosin phosphorylation and $\mathrm{Ca}$ sensitivity with diabetes have been reported in a study of bladder smooth muscle, but changes in Ca sensitisation are not a prominent feature of myometrium [43]. We found that calcium transient amplitude and duration are less in diabetic compared with non-diabetic samples. Therefore, a defect in channel activation, function or expression may occur as a consequence of the diabetic environment. Despite the large number of studies from diabetic animals reporting impaired contractility, few studies have investigated the underlying mechanisms or measured intracellular $\mathrm{Ca}^{2+}$.

Studies of resting membrane potential show no significant changes with diabetes $[36,44,45]$, suggesting that $\mathrm{K}^{+}$ channel activity is unaltered. Reduction in release of $\mathrm{Ca}^{2+}$ from the sarcoplasmic reticulum, $\mathrm{Ca}^{2+}$ sparks, and activators of Ca-activated $\mathrm{K}$ channel (BK) channels was reported in coronary micro-vessels with diabetes in pigs [46]. However, such mechanisms are unlikely to play a role in the uterus as $\mathrm{Ca}^{2+}$ sparks are not present [47]. Consistent with no change in membrane potential, we found no difference in the resting Indo-1 ratios, suggesting no change in resting [Ca], in agreement with data on bladder muscle cells [48].

Stimulation of diabetic uterine tissue with oxytocin and high $\mathrm{K}$ produced large rises in $\mathrm{Ca}$, indicating that these pathways to $\mathrm{Ca}^{2+}$ mobilisation were functional. Thus, our data do not support a role for alteration in the initiation of $\mathrm{Ca}^{2+}$ signalling with diabetes mellitus but rather point to changes in the expression or regulation of L-type $\mathrm{Ca}^{2+}$ channels, perhaps as a consequence of glycosylation of residues. There is evidence to support this in our data and other studies. Wang et al. [40] found a decrease in current density, but no change in cell capacitance, studying rat tail arteries. In cardiac muscles, diabetes is associated with impairment of contraction, and reduced intracellular $\mathrm{Ca}$ [49, $50]$, caused by a reduction in the $\mathrm{Ca}^{2+}$ current. This, in turn, has been attributed to a decrease in $\mathrm{Ca}$ channel function or expression $[49,50]$. Wang et al. also found a stimulatory effect of BAY K-8644 in diabetic preparations, as we did in the uterus, suggesting that the number of $\mathrm{Ca}^{2+}$ channels may be reduced, as it could improve $\mathrm{Ca}^{2+}$ signalling in diabetic myometrium but not restore signals to the level found in non-diabetic samples. A similar argument can be made to explain our high $\mathrm{K}^{+}$data.

In summary, our data point to both histological and cellular changes occurring in diabetic patients that compound to reduce contractility, and $\mathrm{Ca}^{2+}$ signalling. What the mechanistic trigger for this is remains to be investigated in further studies. In particular, the role of changes in insulin receptors and protein glycosylation should be examined.

The impact of diabetes on labour outcome Studies worldwide have shown a much higher $\mathrm{CS}$ rate in diabetic compared with non-diabetic patients [2-4]. Although fetal distress, macrosomia and obesity may contribute to this increased emergency CS rate, prolonged labour and failed induction of labour accounted for $51 \%$ of emergency CS [6]. Therefore, poor myometrial contractility has been suggested as an important factor in diabetic pregnancies, and our data support this conclusion. Before discussing the implications further, we will first discuss some aspects of our patient data.

Our data are based on 40 diabetic myometrial biopsies. With any study of human disease there will be confounding factors and complications, and in diabetes factors such as obesity can complicate interpretation. However, as shown, there were no significant differences in median age, parity, BMI or birthweight between our groups and our data remained significant when confounders were analysed. We also found that the difference held when method of control of glucose was examined; contraction was reduced in both the insulin patients and those exercising dietary control. Thus, we conclude that it is the diabetic environment that is responsible for the reductions in force we have found. 
This impaired contractility, if translated in vivo would lead to poor labour contractions and failure to progress. This, in turn, would be an indication for CS and thus our findings help explain the increased rate of CS in diabetic patients. As we have shown, this impairment persists even with oxytocin stimulation and may help explain why progress in labour may remain poor in diabetic patients, even when oxytocin is administered. Diabetic patients also experience a higher rate of failed labour induction than non-diabetic patients [6]. Although the reasons for this are unknown, we suggest that the poorer contractility in diabetic patients will play a role, although other endocrinological changes such as oestrogen levels cannot be excluded. Nationally and internationally, clinical management of diabetic labours (induction of labour or oxytocin augmentation) is non-specific, that is exactly the same as in non-diabetic patients. Dosages of oxytocin are only altered depending on parity or a history of a previous Caesarean section. Pursuant to our extensive laboratory data, we suggest that all diabetic labours should be considered a unique entity and require a different approach compared with nondiabetic patients. We hypothesise that a higher dosage increment or a longer duration of oxytocin may be required in diabetic labours to counteract the inherent poor uterine contractility, although any adverse outcomes of using higher dosages of oxytocin would need to be considered. We are aware of an ongoing study (HOLDS, www.holds.bham.ac.uk) that is examining the role of higher doses of oxytocin for augmentation in nondiabetic patients. Such augmentation measures may reduce the number of failed inductions as well as the number of women having poor progress in labour.

In conclusion, our data give insight into the effects of diabetes on human myometrium. This is the first study to investigate contractile activity-including that induced by oxytocin. Our findings that, irrespective of the mechanism generating contractions, there is a deficit in force compared with non-diabetic patients adds to the clinical data suggesting that poor myometrial contractility may be an important factor in diabetic pregnancies.

Acknowledgements We are grateful to all the women and staff at Liverpool Women's Hospital who helped us obtain the myometrial biopsies. S. Al-Qahtani was supported by a fellowship from Jazan University, Kingdom of Saudi Arabia, and A. Heath by the Wellcome Trust. We are grateful to Diabetes UK for support.

Contribution statement All authors have contributed to the conception and design, or analysis and interpretation of data, and drafting the article or revising it critically for important intellectual content, and have given final approval of the version to be published.

Duality of interest The authors declare that there is no duality of interest associated with this manuscript.
Open Access This article is distributed under the terms of the Creative Commons Attribution Noncommercial License which permits any noncommercial use, distribution, and reproduction in any medium, provided the original author(s) and source are credited.

\section{References}

1. Bell R, Bailey K, Cresswell T, Hawthorne G, Critchley J, Lewis-Barned N (2008) Trends in prevalence and outcomes of pregnancy in women with pre-existing type I and type II diabetes. BJOG 115:445-452

2. Ehrenberg HM, Durnwald CP, Catalano P, Mercer BM (2004) The influence of obesity and diabetes on the risk of cesarean delivery. Am J Obstet Gynecol 191:969-974

3. Jensen DM, Damm P, Moelsted-Pedersen L et al (2004) Outcomes in type 1 diabetic pregnancies: a nationwide, population-based study. Diabetes Care 27:2819-2823

4. Dunne F, Brydon P, Smith K, Gee H (2003) Pregnancy in women with Type 2 diabetes: 12 years outcome data 1990-2002. Diabet Med 20:734-738

5. Department of Health (2010) NHS Maternity Statistics, England. 2002-2003 Statistical Bulletin

6. Evers IM, de Valk HW, Visser GH (2004) Risk of complications of pregnancy in women with type 1 diabetes: nationwide prospective study in the Netherlands. BMJ 328:915

7. Takoudes TC, Weitzen S, Slocum J, Malee M (2004) Risk of cesarean wound complications in diabetic gestations. Am J Obstet Gynecol 191:958-963

8. Langer O, Yogev Y, Xenakis EM, Brustman L (2005) Overweight and obese in gestational diabetes: the impact on pregnancy outcome. Am J Obstet Gynecol 192:1768-1776

9. Bo S, Menato G, Signorile A et al (2003) Obesity or diabetes: what is worse for the mother and for the baby? Diabetes Metab 29: $175-178$

10. Kjos SL, Berkowitz K, Xiang A (2004) Independent predictors of cesarean delivery in women with diabetes. J Matern Fetal Neonatal Med 15:61-67

11. Crowther CA, Hiller JE, Moss JR, McPhee AJ, Jeffries WS, Robinson JS (2005) Effect of treatment of gestational diabetes mellitus on pregnancy outcomes. N Engl J Med 352:24772486

12. Naylor CD, Sermer M, Chen E, Sykora K (1996) Cesarean delivery in relation to birth weight and gestational glucose tolerance: pathophysiology or practice style? Toronto Trihospital Gestational Diabetes Investigators. JAMA 275:1165-1170

13. Remsberg KE, McKeown RE, McFarland KF, Irwin LS (1999) Diabetes in pregnancy and cesarean delivery. Diabetes Care 22:1561-1567

14. Platt MJ, Davies S, Riedel BJ, Slaughter TF, Mehta SM (2002) Case 4-2002. Near-fatal pulmonary embolism in the immediate postoperative period after off-pump coronary artery bypass graft surgery. J Cardiothorac Vasc Anesth 16:502-507

15. Waring JV, Wendt IR (2000) Effects of anoxia on force, intracellular calcium and lactate production of urinary bladder smooth muscle from control and diabetic rats. J Urol 163:1357-1363

16. Forrest A, Molleman A, Parsons M (2005) The responses to manipulation of extracellular and intracellular calcium are altered in the streptozotocin-diabetic rat colon and ileum. Eur J Pharmacol 509:77-83

17. Fleischhacker E, Esenabhalu VE, Spitaler M et al (1999) Human diabetes is associated with hyperreactivity of vascular smooth muscle cells due to altered subcellular $\mathrm{Ca} 2+$ distribution. Diabetes 48:1323-1330 
18. Inazu M, Sakai Y, Homma I (1991) Contractile responses and calcium mobilization in renal arteries of diabetic rats. Eur $\mathrm{J}$ Pharmacol 203:79-84

19. Pfaffman MA, Ball CR, Darby A, Hilman R (1982) Insulin reversal of diabetes-induced inhibition of vascular contractility in the rat. Am J Physiol 242:H490-H495

20. White RE, Carrier GO (1990) Vascular contraction induced by activation of membrane calcium ion channels is enhanced in streptozotocin-diabetes. J Pharmacol Exp Ther 253:1057-1062

21. McMurtrie EM, Ginsberg GG, Frederick GT, Kirkland JL, Stancel GM, Gardner RM (1985) Effect of a diabetic state on myometrial ultrastructure and isolated uterine contractions in the rat. Proc Soc Exp Biol Med 180:497-504

22. Jawerbaum A, Catafau JR, Gonzalez ET et al (1996) Eicosanoid production, metabolism and contractile activity in the isolated uterus from non-insulin-dependent diabetic rats during late pregnancy. Prostaglandins 51:307-320

23. Franchi AM, Chaud M, Gonzalez ET, Gimeno MA, Gimeno AL (1988) Effects of experimental diabetes on spontaneous contractions, on the output of prostaglandins and on the metabolism of labelled arachidonic acid, in uteri isolated from ovariectomized rats. Influences of estradiol. Prostaglandins 35:191-205

24. Goldraij A, Gimeno AL, Vastik JF, Gimeno MF (1975) Oxytocininduced functional activity of uterine horns from normal and diabetic rats. Effects of insulin and metabolic substrates. Reproduction 2:31-38

25. Kaya T, Cetin A, Cetin M, Sarioglu Y (1999) Effects of endothelin-1 and calcium channel blockers on contractions in human myometrium. A study on myometrial strips from normal and diabetic pregnant women. J Reproductive Med 44:115-121

26. Taggart MJ, Menice CB, Morgan KG, Wray S (1997) Effect of metabolic inhibition on intracellular $\mathrm{Ca}^{2+}$, phosphorylation of myosin regulatory light chain and force in rat smooth muscle. J Physiol 499:485-496

27. Crichton CA, Taggart MJ, Wray S, Smith GL (1993) Effects of $\mathrm{pH}$ and inorganic phosphate on force production in alpha-toxinpermeabilized isolated rat uterine smooth muscle. J Physiol 46:629-645

28. Kupittayanant S, Luckas MJM, Wray S (2002) Effects of inhibitng the sarcoplasmic reticulum on spontaneous and oxytocin-induced contractions of human myometrium. Br J Obstet Gynaec 109:289-296

29. Luckas MJM, Wray S (2000) A comparison of the contractile properties of human myometrium obtained from the upper and lower uterine segments. Br J Obstet Gynaec 107:1309-1311

30. Quenby S, Nik H, Innes B et al (2009) Uterine natural killer cells and angiogenesis in recurrent reproductive failure. Hum Reprod 24:45-54

31. Shmigol AV, Eisner DA, Wray S (1999) The role of the sarcoplasmic reticulum as a $\mathrm{Ca}$ sink in rat uterine smooth muscle cells. J Physiol 520:153-163

32. Mobasheri A, Wray S, Marples D (2005) Distribution of AQP2 and AQP3 water channels in human tissue microarrays. J Mol Histol 36:1-14

33. Noble K, Floyd R, Shmygol A, Shmygol A, Mobasheri A, Wray S (2010) Distribution, expression and functional effects of small conductance Ca-activated potassium (SK) channels in rat myometrium. Cell Calcium 47:47-54
34. Scarborough NL, Carrier GO (1984) Nifedipine and alpha adrenoceptors in rat aorta. II. Role of extracellular calcium in enhanced alpha-2 adrenoceptor-mediated contraction in diabetes. J Pharmacol Exp Ther 231:603-609

35. Waring JV, Wendt IR (2000) Effects of streptozotocin-induced diabetes mellitus on intracellular calcium and contraction of longitudinal smooth muscle from rat urinary bladder. J Urol 163:323-330

36. Hattori Y, Kawasaki H, Fukao M, Gando S, Akaishi Y, Kanno M (1996) Diminishment of contractions associated with depolarization-evoked activation of $\mathrm{Ca} 2+$ channels in diabetic rat aorta. J Vasc Res 33:454-462

37. Carmines PK, Ohishi K, Ikenaga H (1996) Functional impairment of renal afferent arteriolar voltage-gated calcium channels in rats with diabetes mellitus. J Clin Invest 98:2564-2571

38. Fulton DJ, Hodgson WC, Sikorski BW, King RG (1991) Attenuated responses to endothelin- $1, \mathrm{KCl}$ and $\mathrm{CaCl} 2$, but not noradrenaline, of aortae from rats with streptozotocin-induced diabetes mellitus. Br J Pharmacol 104:928-932

39. Abebe W, MacLeod KM (1990) Protein kinase C-mediated contractile responses of arteries from diabetic rats. Br J Pharmacol 101:465-471

40. Wang R, Wu Y, Tang G, Wu L, Hanna ST (2000) Altered L-type $\mathrm{Ca}(2+)$ channel currents in vascular smooth muscle cells from experimental diabetic rats. Am J Physiol Heart Circ Physiol 278: H714-H722

41. Wray S, Jones K, Kupittayanant S et al (2003) Calcium signalling and uterine contractility. J Soc Gynecol Invest 10:252-264

42. Burdyga TV, Wray S (1998) The effect of inhibition of myosin light chain kinase by Wortmannin on intracellular $\left[\mathrm{Ca}^{2+}\right]$, electrical activity and force in phasic smooth muscle. Pflugers Arch 436:801-803

43. Kupittayanant S, Burdyga ThV, Wray S (2001) The effects of inhibiting Rho-associated kinase on force and intracellular calcium in human myometrium. Pflugers Arch 443:112-114

44. Kamata K, Kirisawa H (1998) Changes in electrophysiological properties and noradrenaline response in vas deferens of diabetic rats. Eur J Pharmacol 350:237-241

45. Karicheti V, Santizo C, Zhao W et al (2001) Changes in electrical properties of detrusor smooth muscle in the STZ (streptozotocin)diabetic rat. Urology 57:110-111

46. Mokelke EA, Dietz NJ, Eckman DM, Nelson MT, Sturek M (2005) Diabetic dyslipidemia and exercise affect coronary tone and differential regulation of conduit and microvessel $\mathrm{K}+$ current. Am J Physiol Heart Circ Physiol 288:H1233-H1241

47. Burdyga T, Wray S, Noble K (2007) In situ calcium signaling: no calcium sparks detected in rat myometrium. Ann N Y Acad Sci 1101:85-96

48. Qi J, Curley RM, Belis JA (1992) Cytosol-free calcium concentration in single bladder smooth muscle cells from normal and diabetic rats. Pharmacology 45:90-98

49. Bracken N, Howarth FC, Singh J (2006) Effects of streptozotocininduced diabetes on contraction and calcium transport in rat ventricular cardiomyocytes. Ann N Y Acad Sci 1084:208-222

50. Lu Z, Jiang YP, Xu XH, Ballou LM, Cohen IS, Lin RZ (2007) Decreased L-type $\mathrm{Ca} 2+$ current in cardiac myocytes of type 1 diabetic Akita mice due to reduced phosphatidylinositol 3-kinase signaling. Diabetes 56:2780-2789 